\title{
EVALUACIÓN DE LA SEROPROTECCIÓN CONTRA SARAMPIÓN, RUBÉOLA Y HEPATITIS B EN NIÑOS MENORES DE CINCO AÑOS DEL PERÚ, 2011
}

\author{
Víctor Fiestas Solórzano ${ }^{1, a}$, Marco Gonzáles Noriega ${ }^{1, b}$, Fabián Fiestas ${ }^{1, c}$, \\ Edwin Cabezudo ${ }^{2, d}$, Magna Suárez ${ }^{3, d}$, Víctor Suárez ${ }^{1, a}$
}

\begin{abstract}
RESUMEN
Objetivos. Estimar la prevalencia de anticuerpos contra sarampión, rubéola y hepatitis B en niños de 1 a 4 años del Perú. Materiales y métodos. Se realizó una encuesta nacional basada en la aplicación de un cuestionario y obtención de muestra de sangre capilar en papel de filtro para el estudio de anticuerpos contra sarampión, rubéola y hepatitis $B$ en niños de 1 a 4 años. Se utilizó un muestreo probabilístico, estratificado y multietápico con inferencia a nivel nacional y siete ámbitos de estudio: Lima metropolitana, resto de costa urbana, costa rural, sierra urbana, sierra rural, selva urbana y selva rural. Las muestras de sangre capilar fueron procesadas siguiendo protocolos estandarizados para la determinación de anticuerpos mediante técnica de ELISA utilizando reactivos comerciales. Resultados. Se encontró una prevalencia nacional de 91,6\% (IC95\%: 90,6-92,7\%), 91,3\% (IC 95\%: 90,3-92,4\%) y 95,9\% (IC 95\%: 95,0-96,8\%) para anticuerpos contra sarampión, rubéola y hepatitis B respectivamente. No se evidenció diferencias significativas de las prevalencias entre los diferentes ámbitos de estudio y en los diferentes estratos socioeconómicos de los conglomerados. Conclusiones. En niños de 1 a 4 años se ha estimado una prevalencia nacional de anticuerpos contra sarampión y rubéola entre 90-93\%, mientras que para anticuerpos contra hepatitis B (anti-HBsAg) entre 95-97\%.
\end{abstract}

Palabras clave: Sarampión; Virus de la rubéola; Hepatitis B; Anticuerpos; Niño (fuente: DeCS BIREME).

\section{EVALUATION OF THE SEROPROTECTION AGAINST MEASLES, RUBELLA AND HEPATITIS B IN CHILDREN UNDER 5 YEARS OF AGE IN PERU, 2011}

\begin{abstract}
Objectives. To estimate the prevalence of antibodies against measles, rubella and hepatitis B in children aged between 1 and 4 years in Peru. Materials and methods. A national survey was conducted based on a questionnaire and capillary blood sample taken on filter paper in order to study antibodies against measles, rubella and hepatitis $B$ in children from 1 to 4 years of age. A stratified, multistage, probability sampling design was used to be representative at the national level and at level of seven ambits, including the Metropolitan Lima Area, the rest of the urban coast, the rural coast, the urban highlands, the rural highlands, the urban jungle and the rural jungle. The capillary blood samples were processed according to the standardized protocols for detection of antibodies using the ELISA technique and commercial reagents. Results. The survey showed a national prevalence of antibodies against measles, rubella and hepatitis B of $91.6 \%$ (Cl 95\%: 90.6\%; 92.7\%), 91.3\% (Cl 95\%: 90.3\%; 92.4\%) and 95.9\% (Cl 95\%: 95.0\%; 96.8\%) respectively. There was no evidence of significant differences in the prevalence among the ambits of study or among the socioeconomic strata of the conglomerates for any of the three types of antibodies. Conclusions. In children from 1 to 4 years of age, the national prevalence of antibodies against measles and Rubella was between $90-93 \%$, while the prevalence of antibodies against Hepatitis B (anti-HBsAg) was between $95-97 \%$.
\end{abstract}

Key words: Measles; Rubella virus; Hepatitis B; Antibodies; Child (source: MeSH NLM).

\footnotetext{
Unidad de Análisis y Generación de Evidencias en Salud Pública (UNAGESP), Instituto Nacional de Salud. Lima, Perú

Laboratorio de Sarampión y Rubéola, Instituto Nacional de Salud. Lima, Perú.

Laboratorio de Hepatitis y Enterovirus, Instituto Nacional de Salud. Lima, Perú.

Médico infectólogo; ${ }^{\mathrm{b}}$ médico epidemiólogo; ${ }^{\mathrm{C}}$ estadístico; ${ }^{\mathrm{d}}$ biólogo

Recibido: 30-07-12 Aprobado: 17-10-12

* Este artículo se basa en el informe técnico "Estudio de la seroprevalencia contra sarampión, rubéola y hepatitis B en niños de 1 a 4 años del Perú" disponible en la página web de Notas Técnicas UNAGESP del Instituto Nacional de Salud de Perú.
}

Citar como: Fiestas Solórzano V, Gonzáles Noriega M, Fiestas F, Cabezudo E, Suárez M, Suárez V. Evaluación de la seroprotección contra sarampión, rubéola y hepatitis b en niños menores de cinco años del Perú, 2011. Rev Peru Med Exp Salud Publica. 2012;29(4):437-43. 


\section{INTRODUCCIÓN}

La inmunización mediante vacunación es una de las medidas más costo-efectivas en salud pública que han permitido evitar millones de muertes y discapacidades en la población. Su éxito ha sido reconocido a nivel mundial con la erradicación de la viruela en el año 1977; en el continente americano con la eliminación de la poliomielitis en el año 1991, y la interrupción de la transmisión del virus sarampión desde el año 2002 y virus rubéola desde el año $2009{ }^{(1)}$. Sin embargo, estos últimos agentes aún no han sido erradicados del mundo y persiste el riesgo de propagación internacional; por ello, para evitar su reintroducción en las Américas es necesario sostener un sistema eficaz de vigilancia epidemiológica y continuar inmunizando a la población objetivo manteniendo coberturas mínimas de $95 \%$ según las recomendaciones de la Organización Panamericana de la Salud (OPS) (2).

La última gran epidemia de sarampión en el Perú ocurrió en el año 1992: causó 210 muertes con una tasa de letalidad de $0,92 \%$ y una incidencia acumulada de 101,4 casos por 100000 habitantes. El último caso autóctono se identificó en la semana epidemiológica 13 del año 2000 en el distrito de Ventanilla perteneciente a la Provincia Constitucional del Callao (3).

En relación con rubéola, las últimas epidemias en el Perú se presentaron entre los años 2000-2001 y 2004-2006, que afectaron con mayor intensidad a los departamentos de Arequipa, Ica, Tacna y Lima. Luego de su eliminación, muchos casos notificados inicialmente como sarampión fueron confirmados como rubéola hasta fines del año 2006, cuando se notificaron los últimos casos autóctonos de rubéola y síndrome de rubéola congénita (SRC) en el Perú (3). Para consolidar esta eliminación en el año 2006 se realizó una campaña nacional de vacunación contra sarampión y rubéola a todas las personas de 2 a 39 años, que alcanzó una cobertura certificada por la OPS de $98,2 \%{ }^{(4)}$.

Actualmente, la norma técnica del esquema nacional de vacunación establece que la primera dosis de vacuna SPR se aplica a los 12 meses y el primer refuerzo a los 4 años ${ }^{(5)}$. Asimismo, se mantiene una vigilancia conjunta de sarampión y rubéola en todo el país, que permite una oportuna identificación de casos importados a partir de países endémicos como en el año 2008, cuando se identificó en Lima un caso de sarampión importado procedente de la India que no produjo casos secundarios por contacto ${ }^{(6)}$.

En cuanto a la hepatitis B, el Ministerio de Salud del Perú (MINSA) incorporó la vacuna desde el año 1996; inicialmente para niños menores de un año residentes en áreas de mediana y alta endemicidad, y desde el año 2003 se universalizó a nivel nacional para todos los menores de un año; en la actualidad se brinda una dosis al recién nacido y tres dosis en la vacuna pentavalente a los 2, 4 y 6 meses ${ }^{(5)}$. En el año 2008 se realizó la campaña nacional de vacunación contra hepatitis B en la población de 2 a 19 años y grupos con factores de riesgo, con el objetivo de avanzar en un control acelerado de la hepatitis $B{ }^{(7)}$. En el año 2010 se realizó un estudio en 69 comunidades nativas kandozi y chapra de la región Loreto donde se encontró la prevalencia de $1,9 \%$ de portadores crónicos de $\mathrm{HBsAg}$, pero ninguno en menores de 6 años, lo cual se considera un gran logro de la inmunización contra hepatitis $\mathrm{B}$ en el país ${ }^{(8)}$.

En general, las coberturas de vacunación son un indicador del estado de inmunización de la población y se definen como la proporción estimada de la población objetivo que ha recibido las dosis de vacunas recomendadas. Las estrategias recomendadas para mantener la eliminación de las enfermedades inmunoprevenibles incluyen coberturas mínimas de 95\% mediante actividades de vacunación regular o jornadas nacionales de vacunación ${ }^{(9)}$.

Según el MINSA, en el año 2010 la cobertura de vacunación para niños de un año fue de 95,3\% para la vacuna BCG; $92,1 \%$ para la tercera dosis de vacuna OPV; $92,5 \%$ para la tercera dosis de vacuna pentavalente, y 93,9\% para vacuna SPR, correspondiendo los valores más bajos a las regiones Puno y Huancavelica (10). Otra fuente de información en el país es la Encuesta Demográfica y Salud Familiar (ENDES) realizada periódicamente por el Instituto Nacional de Estadística e Informática (INEI) y cuya información sobre el estado de vacunación del niño se basa en la tarjeta de vacunación o el reporte de la madre; según la cual, para el año 2010 , encontró que el porcentaje de niños y niñas de 1829 meses de edad con vacuna BCG fue 90,0\%; tercera dosis de vacuna DPT 73,7\%; tercera dosis de vacuna OPV $76,4 \%$, y vacuna antisarampionosa $83,4 \%{ }^{(11)}$.

La presente investigación tuvo como objetivo estimar la prevalencia de anticuerpos contra sarampión, rubéola y hepatitis $B$ en niños de 1 a 4 años, permitiendo evaluar la efectividad de las actividades de inmunización desarrolladas en el país.

\section{MATERIALES Y MÉTODOS}

Se realizó un estudio descriptivo y transversal en niños de 1 a 4 años de los 24 departamentos de Perú, entre los meses de noviembre de 2011 y enero de 2012. Se utilizó un diseño probabilístico, estratificado 
y multietápico que tuvo como marco muestral el Censo Nacional de Población y Vivienda del 2007. El listado de conglomerados seleccionados de cada departamento con sus respectivos reemplazos y mapas de ubicación fueron proporcionados por el INEI. En cada conglomerado se censaron las viviendas que tenían población objetivo y se eligieron aleatoriamente cinco hogares cuando el conglomerado era de área urbana, y diez hogares cuando el conglomerado era de área rural. Finalmente, de cada hogar seleccionado se enroló a un niño o niña de 1 a 4 años.

Siguiendo las recomendaciones de la OMS ${ }^{(12)}$ se calculó un tamaño de muestra de 5976 niños con un nivel de confianza de $95 \%$; una prevalencia de protección serológica esperada de 50\%; una tasa de no respuesta de $10 \%$; un margen de error de $5 \%$; un efecto de diseño de 2; con inferencia nacional y en siete ámbitos geográficos: Lima metropolitana, resto de costa urbana, costa rural, sierra urbana, sierra rural, selva urbana y selva rural.

\section{PROCEDIMIENTOS}

La presente encuesta nacional se basó en la aplicación de un cuestionario y la obtención de muestra de sangre capilar en papel de filtro para el estudio de anticuerpos IgG contra sarampión, IgG contra rubéola y marcadores de hepatitis B (HBsAg, anti-HBc y anti-HBsAg). El cuestionario recolectó información sobre el niño y los padres, datos de vacunación, así como la exploración de conocimientos, actitudes y prácticas de los padres, sobre aspectos de vacunación e inmunización.

Con una lanceta estéril y previa limpieza de la zona, se obtuvieron gotas de sangre capilar del pulpejo del dedo medio de la mano que fueron recogidas en papel filtro Whatman $903 \AA$, llenando cinco círculos de $12,5 \mathrm{~mm}$ de diámetro que estaban impresos en el papel y que luego se dejaban secar por cuatro horas a temperatura ambiente antes de ser colocadas en una bolsa de cierre hermético con dos bolsas pequeñas silica gel, las cuales fueron conservadas en refrigeración $\left(4-8{ }^{\circ} \mathrm{C}\right)$ hasta su procesamiento en Lima.

Las muestras en papel filtro fueron procesadas antes de un mes desde su obtención, siguiendo protocolos estandarizados en estudios previos para la determinación de anticuerpos contra hepatitis $\mathrm{B}{ }^{(13)}$, sarampión y rubéola ${ }^{(14)}$. Se recortaron los círculos con gotas de sangre seca con los siguientes diámetros: $12,5 \mathrm{~mm}$ para IgG antisarampión, IgG antirubéola y anti HBsAg, $6 \mathrm{~mm}$ para HBsAg y anti HBc total; a los cuales se añadieron PBS-BSA 0,5\% (buffer fosfato salino + albúmina sérica bovina) en las siguientes cantidades: $300 \mathrm{uL}$ para IgG antisarampión, IgG antirubéola y anti HBsAg, 700 uL para HBsAg y anti $\mathrm{HBc}$ total, en crioviales de $2,0 \mathrm{~mL}$, y fueron incubados a $4-8{ }^{\circ} \mathrm{C}$ durante $18-24$ horas.

Posteriormente, las muestras fueron procesadas mediante técnica de inmunoensayo enzimático ELISA utilizando reactivos comerciales para marcadores de hepatitis B (Bioelisa HBsAg 3.0 BIOKIT®, Bioelisa anti$\mathrm{HBc}$ BIOKIT® y Bioelisa anti-HBs BIOKIT®), anticuerpos IgG antisarampión y antirubéola (Vircell囚). La condición de seroprotección contra sarampión y rubéola fue dada por la presencia de los anticuerpos IgG correspondientes y para hepatitis $\mathrm{B}$ fue dada por la determinación de anticuerpos anti $\mathrm{HBsAg} \geq 10 \mathrm{mUl} / \mathrm{mL}$. Para el control de calidad interno del procesamiento de las muestras, se utilizó el gráfico de Levey-Jennings en la fase analítica y las reglas de Westgard en la fase posanalítica.

\section{ANÁLISIS ESTADÍSTICO}

Los datos fueron ingresados en el programa Epi Info ${ }^{\mathrm{TM}}$ versión 3.5.1, 2008 (CDC; Atlanta, GA) mediante doble digitación. Para la estimación de las prevalencias de anticuerpos contra sarampión, rubéola y hepatitis $B$ en los ámbitos geográficos se usó el módulo de estimación de muestras complejas del programa Stata ${ }^{\circledR}$ versión 11.2 (StataCorp; College Station, TX). Para el cálculo del factor de expansión se utilizaron las probabilidades de selección de los conglomerados, las viviendas seleccionadas y los niños de la población objetivo.

\section{ASPECTOS ÉTICOS}

El estudio y el consentimiento informado fueron aprobados por el Comité de Ética en Investigación del Instituto Nacional de Salud del Perú (código 007-2011).

\section{RESULTADOS}

Se invitó a participar en el estudio a 6305 familias, de las cuales se enrolaron 6167 niños (tasa de respuesta de $97,8 \%$ ). Sin embargo, el análisis se realizó con la información de 5906 niños participantes, luego de excluir aquellos con muestras de sangre en papel filtro que no cumplieron con los estándares de calidad requeridos, o cuestionarios que no tenían registrada la información suficiente para el análisis poblacional $(4,2 \%$ de pérdida).

En la Tabla 1 se puede observar las principales características de la población estudiada. El 50,6\% de los participantes fueron varones. El $84,5 \%$ se vacunaron en establecimientos del MINSA, el 10,0\% en establecimientos de ESSALUD y $2,5 \%$ en otros establecimientos del sector (fuerzas armadas, fuerzas policiales, municipales y 
Tabla 1. Características de la población estudiada de 1 a 4 años, Perú 2011.

\begin{tabular}{|c|c|c|c|c|c|c|c|c|c|c|c|c|c|c|c|c|}
\hline \multirow[t]{2}{*}{ Variable } & \multicolumn{2}{|c|}{$\begin{array}{l}\text { Lima } \\
\text { Metropoli- } \\
\text { tana }\end{array}$} & \multicolumn{2}{|c|}{$\begin{array}{l}\text { Resto } \\
\text { de costa } \\
\text { urbana }\end{array}$} & \multicolumn{2}{|c|}{ Costa rural } & \multicolumn{2}{|c|}{$\begin{array}{c}\text { Sierra } \\
\text { urbana }\end{array}$} & \multicolumn{2}{|c|}{ Sierra rural } & \multicolumn{2}{|c|}{$\begin{array}{c}\text { Selva } \\
\text { urbana }\end{array}$} & \multicolumn{2}{|c|}{ Selva rural } & \multicolumn{2}{|c|}{ Total } \\
\hline & N. ${ }^{\circ}$ & $(\%)$ & N. ${ }^{\circ}$ & $(\%)$ & N. ${ }^{\circ}$ & $(\%)$ & N. ${ }^{\circ}$ & $(\%)$ & N. ${ }^{\circ}$ & $(\%)$ & N. ${ }^{\circ}$ & (\%) & N. ${ }^{\circ}$ & $(\%)$ & N. ${ }^{\circ}$ & (\%) \\
\hline \multicolumn{17}{|c|}{ Grupo de edad } \\
\hline 1 año & 229 & $(25,4)$ & 203 & $(23,9)$ & 147 & $(18,3)$ & 204 & $(22,1)$ & 194 & $(24,5)$ & 201 & $(22,5)$ & 149 & $(20,0)$ & 1327 & $(22,5)$ \\
\hline 2 años & 263 & $(29,2)$ & 230 & $(27,0)$ & 226 & $(28,1)$ & 234 & $(25,4)$ & 218 & $(27,5)$ & 257 & $(28,8)$ & 200 & $(26,8)$ & 1628 & $(27,6)$ \\
\hline 3 años & 229 & $(25,4)$ & 211 & $(24,8)$ & 230 & $(28,6)$ & 234 & $(25,4)$ & 199 & $(25,1)$ & 238 & $(26,7)$ & 191 & $(25,6)$ & 1532 & $(25,9)$ \\
\hline 4 años & 171 & $(19,0)$ & 185 & $(21,7)$ & 186 & $(23,1)$ & 234 & $(25,4)$ & 160 & $(20,2)$ & 170 & $(19,1)$ & 193 & $(25,9)$ & 1299 & $(22,0)$ \\
\hline sin dato & 8 & $(0,9)$ & 22 & $(2,6)$ & 15 & $(1,9)$ & 15 & $(1,6)$ & 22 & $(2,8)$ & 26 & $(2,9)$ & 12 & $(1,6)$ & 120 & $(2,0)$ \\
\hline \multicolumn{17}{|l|}{ Sexo } \\
\hline Hombre & 441 & $(49,0)$ & 433 & $(50,9)$ & 405 & $(50,4)$ & 477 & $(51,8)$ & 395 & $(49,8)$ & 469 & $(52,6)$ & 366 & $(49,1)$ & 2986 & $(50,6)$ \\
\hline Mujer & 459 & $(51,0)$ & 418 & $(49,1)$ & 399 & $(49,6)$ & 444 & $(48,2)$ & 398 & $(50,2)$ & 423 & $(47,4)$ & 379 & $(50,9)$ & 2920 & $(49,4)$ \\
\hline \multicolumn{17}{|c|}{ Lugar de vacunación } \\
\hline MINSA & 705 & $(78,3)$ & 656 & $(77,1)$ & 704 & $(87,6)$ & 751 & $(81,5)$ & 724 & $(91,3)$ & 738 & $(82,7)$ & 714 & $(95,8)$ & 4992 & $(84,5)$ \\
\hline ESSALUD & 106 & $(11,8)$ & 152 & $(17,9)$ & 47 & $(5,8)$ & 131 & $(14,2)$ & 37 & $(4,7)$ & 101 & $(11,3)$ & 16 & $(2,1)$ & 590 & $(10,0)$ \\
\hline Otros & 68 & $(7,6)$ & 17 & $(2,0)$ & 5 & $(0,6)$ & 17 & $(1,8)$ & 9 & $(1,1)$ & 26 & $(2,9)$ & 3 & $(0,4)$ & 145 & $(2,5)$ \\
\hline Sin dato & 21 & $(2,3)$ & 26 & $(3,1)$ & 48 & $(6,0)$ & 22 & $(2,4)$ & 23 & $(2,9)$ & 27 & $(3,0)$ & 12 & $(1,6)$ & 179 & $(3,0)$ \\
\hline \multicolumn{17}{|c|}{ Estrato socioeconómico del conglomerado } \\
\hline Alto & 159 & $(17,7)$ & 55 & $(6,5)$ & 0 & $(0,0)$ & 32 & $(3,5)$ & 0 & $(0,0)$ & 11 & $(1,2)$ & 0 & $(0,0)$ & 257 & $(4,4)$ \\
\hline Medio & 328 & $(36,4)$ & 112 & $(13,2)$ & 0 & $(0,0)$ & 78 & $(8,5)$ & 0 & $(0,0)$ & 29 & $(3,3)$ & 0 & $(0,0)$ & 547 & $(9,3)$ \\
\hline Bajo & 268 & $(29,8)$ & 360 & $(42,3)$ & 0 & $(0,0)$ & 350 & $(38,0)$ & 0 & $(0,0)$ & 288 & $(32,3)$ & 0 & $(0,0)$ & 1266 & $(21,4)$ \\
\hline Muy bajo & 145 & $(16,1)$ & 324 & $(38,1)$ & 0 & $(0,0)$ & 461 & $(50,1)$ & 0 & $(0,0)$ & 564 & $(63,2)$ & 0 & $(0,0)$ & 1494 & $(25,3)$ \\
\hline Rural & 0 & $(0,0)$ & 0 & $(0,0)$ & 804 & $(100,0)$ & 0 & $(0,0)$ & 793 & $(100,0)$ & 0 & $(0,0)$ & 745 & $(100,0)$ & 2342 & $(39,7)$ \\
\hline Total & 900 & $(15,2)$ & 851 & $(14,4)$ & 804 & $(13,6)$ & 921 & $(15,6)$ & 793 & $(13,4)$ & 892 & $(15,1)$ & 745 & $(12,6)$ & 5906 & $(100,0)$ \\
\hline
\end{tabular}

privados). Solo $60,7 \%$ de los participantes contaban con tarjeta de vacunación al momento de la entrevista, siendo menor la proporción a mayor edad del niño.

\section{SARAMPIÓN - RUBÉOLA - HEPATITIS B}

En la Tabla 2 se aprecia que el valor a nivel nacional de la prevalencia de anticuerpos contra sarampión (lgG antisarampión), rubéola (IgG antirubéola) y hepatitis $B$ (anti HbsAg) fue de 91,6\% (IC95\%: 90,6-92,7\%); 91,3\%
(IC95\%: 90,3-92,4\%) y 95,9\% (IC95\%: 95,0-96,8\%), respectivamente. Del mismo modo, para los tres casos, la prevalencia fue similar en todos los ámbitos de estudio con variaciones que no llegaron a ser significativas.

En la Tabla 3 se observa que no hubo diferencia en la prevalencia de anticuerpos contra sarampión y rubéola según sexo, lugar de vacunación y estrato socioeconómico del conglomerado. Sin embargo, tanto en sarampión como en rubéola, se encontraron diferencias entre las

Tabla 2. Prevalencia de anticuerpos lgG antisarampión, IgG antirubéola y Anti HBsAg por ámbito de estudio, Perú 2011.

\begin{tabular}{lcccccccccc}
\hline \multirow{2}{*}{ Ámbito geográfico } & \multirow{2}{*}{ N. $^{\circ}$} & \multicolumn{3}{c}{ IgG antisarampión } & \multicolumn{3}{c}{ IgG antirubéola } & \multicolumn{2}{c}{ Anti HBsAg } \\
\cline { 3 - 11 } & & \multicolumn{2}{c}{ Prevalencia (IC95\%) } & ED & Prevalencia (IC95\%) & ED & Prevalencia (IC95\%) & ED \\
\hline Nacional & 5906 & 91,6 & $(90,6-92,7)$ & 2,2 & 91,3 & $(90,3-92,4)$ & 2,3 & 95,9 & $(95,0-96,8)$ & 2,9 \\
Urbano & 3564 & 91,3 & $(90,1-92,6)$ & 2,0 & 91,1 & $(89,8-92-4)$ & 2,1 & 95,6 & $(94,4-96,7)$ & 3,3 \\
Rural & 2342 & 92,3 & $(90,2-94,3)$ & 2,8 & 91,9 & $(89,8-93,9)$ & 2,8 & 96,6 & $(95,4-97,7)$ & 2,0 \\
Resto de & 851 & 93,1 & $(91,1-95,0)$ & 1,7 & 92,3 & $(90,1-94,4)$ & 1,8 & 96,5 & $(94,2-98,8)$ & 4,4 \\
costa urbano & 804 & 93,7 & $(90,5-96,9)$ & 1,4 & 92,1 & $(87,7-96,4)$ & 2,0 & 96,9 & $(94,5-99,2)$ & 1,5 \\
Resto de costa rural & 921 & 92,8 & $(90,7-94,9)$ & 1,6 & 92,7 & $(90,5-94,8)$ & 1,6 & 95,5 & $(93,4-97,5)$ & 2,4 \\
Sierra urbano & 793 & 91,1 & $(88,2-94,1)$ & 3,2 & 91,1 & $(88,1-94,0)$ & 3,2 & 96,4 & $(94,8-98,0)$ & 2,3 \\
Sierra rural & 892 & 90,5 & $(87,8-93,2)$ & 1,0 & 90,4 & $(87,7-93,1)$ & 1,0 & 95,3 & $(92,4-98,2)$ & 2,2 \\
Selva urbano & 745 & 94,4 & $(91,5-97,3)$ & 1,6 & 94,1 & $(91,2-97,0)$ & 1,6 & 96,9 & $(94,8-98,9)$ & 1,4 \\
Selva rural & 900 & 89,5 & $(87,2-91,9)$ & 2,5 & 89,6 & $(87,2-92,0)$ & 2,6 & 95,1 & $(93,1-97,1)$ & 3,5 \\
\hline Lima metropolitana & 900 & & & & & &
\end{tabular}

IC 95\%: intervalo de confianza 95\%. ED: efecto de diseño. 
Tabla 3. Prevalencia de anticuerpos antisarampión, IgG antirubéola y anti-HBsAg según sexo, edad, lugar de vacunación y estrato socioeconómico del conglomerado, Perú 2011.

\begin{tabular}{|c|c|c|c|c|c|c|c|c|c|c|}
\hline \multirow{2}{*}{ Variable } & \multirow{2}{*}{ N. ${ }^{\circ}$} & \multicolumn{3}{|c|}{ IgG antisarampión } & \multicolumn{3}{|c|}{ IgG antirubéola } & \multicolumn{3}{|c|}{ Anti HBsAg } \\
\hline & & \multicolumn{2}{|c|}{ Prevalencia (IC95\%) } & ED & \multicolumn{2}{|c|}{ Prevalencia (IC95\%) } & ED & \multicolumn{2}{|c|}{ Prevalencia (IC95\%) } & ED \\
\hline Hombre & 2986 & 91,3 & $(89,7-92,8)$ & 2,3 & 91,1 & $(89,5-92,6)$ & 2,3 & 96,2 & $(95,2-97,3)$ & 2,3 \\
\hline Mujer & 2920 & 92,0 & $(90,6-93,5)$ & 2,2 & 91,6 & $(90,1-93,1)$ & 2,2 & 95,5 & $(94,4-96,7)$ & 2,2 \\
\hline \multicolumn{11}{|l|}{ Edad } \\
\hline 1 año & 1327 & 80,5 & $(77,5-83,5)$ & 2,1 & 79,6 & $(76,5-82,7)$ & 2,1 & 95,9 & $(94,2-97,6)$ & 2,5 \\
\hline 2 años & 1628 & 94,7 & $(92,8-96,6)$ & 3,1 & 94,7 & $(92,7-96,6)$ & 3,2 & 96,1 & $(94,7-97,5)$ & 2,2 \\
\hline 3 años & 1532 & 95,4 & $(93,9-97,0)$ & 2,2 & 95,1 & $(93,5-96,8)$ & 2,4 & 95,6 & $(94,1-97,1)$ & 2,0 \\
\hline 4 años & 1299 & 95,9 & $(94,3-97,5)$ & 2,1 & 96,1 & $(94,5-97,6)$ & 2,1 & 96,3 & $(94,9-97,7)$ & 1,8 \\
\hline \multicolumn{11}{|c|}{ Lugar de vacunación } \\
\hline MINSA & 4992 & 92,0 & $(90,9-93,2)$ & 2,3 & 91,8 & $(90,6-93,0)$ & 2,4 & 96,1 & $(95,2-96,9)$ & 2,7 \\
\hline ESSALUD & 590 & 91,8 & $(88,9-94,7)$ & 1,8 & 90,8 & $(87,5-94,0)$ & 2,0 & 95.0 & $(92,4-97,5)$ & 2,2 \\
\hline Otros & 145 & 86,7 & $(78,2-95,2)$ & 2,5 & 86,1 & $(77,6-94,7)$ & 2,4 & 92,7 & $(85,2-100,0)$ & 3,3 \\
\hline \multicolumn{11}{|c|}{ Estrato social del conglomerado } \\
\hline Alto & 257 & 93,4 & $(89,3-97,6)$ & 1,9 & 92,6 & $(88,4-96,8)$ & 1,8 & 93,3 & $(88,4-98,3)$ & 2,7 \\
\hline Medio & 547 & 91,6 & $(88,7-94,5)$ & 2,1 & 91,2 & $(88,1-94,2)$ & 2,2 & 96,5 & $(94,6-98,3)$ & 2,0 \\
\hline Bajo & 1266 & 91,2 & $(89,2-93,2)$ & 1,8 & 91,1 & $(89,1-93,2)$ & 1,9 & 96,3 & $(94,6-97,9)$ & 3,0 \\
\hline Muy bajo & 1494 & 91,0 & $(88,9-93,1)$ & 2,1 & 90,8 & $(88,7-92,9)$ & 2,1 & 94,9 & $(92,7-97,1)$ & 4,0 \\
\hline Área rural & 2342 & 92,3 & $(90,2-94,3)$ & 2,8 & 91,9 & $(89,8-93,9)$ & 2,8 & 96,6 & $(95,4-97,7)$ & 2,0 \\
\hline
\end{tabular}

IC 95\%: intervalo de confianza 95\%. ED: efecto de diseño.

prevalencias del grupo de un año de edad en relación al grupo de 2 a 4 años.

En relación a la hepatitis $B$, se observó que no hubo diferencia en la prevalencia de anticuerpos según sexo, grupo etario, lugar de vacunación o estrato socioeconómico de los conglomerados. Asimismo, ninguna de las muestras recolectadas resultó positiva para HBsAg o anti-HBc total, por lo cual ningún niño participante en el estudio mostró evidencia serológica de infección antigua con virus de la hepatitis $B$.

\section{DISCUSIÓN}

Este es el primer estudio de seroprevalencia con representatividad nacional que se realiza para determinar la protección inmunológica contra sarampión, rubéola y hepatitis $B$ en niños de 1 a 4 años de nuestro país.

Desde hace varias décadas, la comunidad científica ha sugerido el uso del papel filtro como un método rápido y fácil para la obtención de muestra de sangre en los estudios de vigilancia de hepatitis, sarampión y rubéola (15-18). Los estudios evidencian que el uso de muestras de sangre capilar en papel filtro conservadas en cadena de frío tiene una sensibilidad de $98,4 \%$ y una especificidad de $97,2 \%$ para la detección de IgG rubéola e IgG sarampión en comparación con muestras de suero a partir de sangre venosa, usando reactivos comerciales ${ }^{(19-20)}$. Para el caso de anti-HBc, HBsAg y anti-HBsAg tiene una sensibilidad de 90,$5 ; 97,6$ y $78,0 \%$, así como una especificidad de 92,$6 ; 96,7$ y $97,3 \%$ respectivamente ${ }^{(13)}$. En un estudio piloto, realizado previamente, para evaluar el uso de papel filtro en nuestra población objetivo se obtuvieron resultados concordantes con lo descrito en la literatura.

En los últimos años, el Estado peruano ha invertido mayor presupuesto en las actividades de inmunización por vacuna con el objetivo de reducir de manera costoefectiva la morbi-mortalidad por enfermedades como sarampión, rubéola y hepatitis $B$. Una manera de evaluar el logro de esta intervención en la población objetivo es calculando las coberturas de vacunación alcanzadas a través de actividades de vacunación regular o jornadas nacionales de vacunación, las cuales según las recomendaciones de la OPS deben ser igual o mayores a $95 \%{ }^{(2)}$.

Sin embargo, los valores de las coberturas de vacunación pueden no reflejar las dificultades existentes en el nivel local, tales como el pobre acceso a los sistemas de salud, debilidades en la captación y seguimiento de la población objetivo, deficiencias en el sistema de información entre otros. ${ }^{(21)}$. Asimismo, los registros de inmunización pueden tener un limitado valor predictivo y no se aconsejan como evidencia de protección inmunológica en la población ${ }^{(22)}$. Por ello 
es que la OMS recomienda que los países realicen encuestas periódicas para validar las coberturas de vacunación notificadas administrativamente ${ }^{(23)}$.

En la presente investigación se establece una prevalencia nacional de 91,6\% (IC 95\%: 90,6 - 92,7\%) para anticuerpos IgG contra sarampión y $91,3 \%$ (IC 95\%: 90,3 - 92,4\%) para anticuerpos IgG contra rubéola en niños de 1 a 4 años. Estos datos se deben interpretar teniendo en cuenta que en el Perú desde el año 2000 y 2007 no circula virus sarampión y rubéola, respectivamente, y que los niños participantes no tuvieron mas de 4 años 11 meses, 29 días al momento de la encuesta. De esta manera, los resultados de prevalencia de anticuerpos protectores obtenidos en esta población resultan significativos en el proceso de consolidación de la eliminación de sarampión, rubéola y síndrome de rubéola congénita (SRC) en el país. Sin embargo, es necesario tener en consideración que $7-10 \%$ de los niños no presentaron anticuerpos protectores, con mayor probabilidad en el grupo de un año de edad, por lo cual se requerirá profundizar los estudios en este grupo de edad para identificar y evaluar factores relacionados con esta baja seroprevalencia.

Por otro lado, es necesario tener en cuenta que una limitación del estudio para la interpretación de los resultados es haberse realizado en las últimas semanas de un barrido nacional contra sarampión, rubéola y poliomielitis. Ello hace que los resultados de prevalencia de anticuerpos contra sarampión y rubéola obtenidos no distingan entre la seroprotección lograda mediante vacunación regular y la campaña de vacunación mencionada.

En relación a los valores de anticuerpos hallados de anticuerpos anti-HBsAg, se establece una prevalencia nacional de 95,9\% (IC 95\%: 95,0 - 96,8\%), lo cual representa una óptima protección de los niños de 1 a 4 años en ausencia de evidencia serológica de infección antigua (HBsAg y anti-HBc), lo cual es consistente con estudios realizados recientemente en algunas zonas del país ${ }^{(8)}$. Estos resultados sugieren que la vacunación conjuntamente con otras intervenciones (24) están logrando un avance importante en el control de la hepatitis $\mathrm{B}$ en el Perú.

En el presente artículo solo se presentarán los resultados correspondientes al objetivo principal del estudio, en una próxima publicación se informarán los resultados del análisis de otras variables estudiadas que pudieran estar relacionadas con los resultados obtenidos, como los conocimientos, actitudes y práctica de los padres, sobre aspectos de vacunación e inmunización.

En conclusión, para niños de 1 a 4 años se ha estimado una prevalencia nacional de anticuerpos IgG contra sarampión y rubéola entre $90-93 \%$, mientras que para anticuerpos contra hepatitis B (anti-HBsAg) entre 95-97\%. Estas prevalencias fueron homogéneas en los siete ámbitos de estudio en el territorio nacional y en los diferentes estratos socioeconómicos de los conglomerados.

Agradecimientos: a las DISA, DIRESA y GERESA del país por su apoyo en la realización del estudio. Al Instituto de Medicina Tropical "Daniel Alcides Carrión" de la Universidad Nacional Mayor de San Marcos por brindar facilidades para el procesamiento de las muestras.

Contribuciones de autoría: VF, MG y FF participaron en la concepción del estudio. VF, MG, EC y MS en la recolección de datos; VF, MG y FF en el análisis e interpretación de datos; MG en la asesoría estadística, VS en la asesoría técnica. VF y FF realizaron la redacción del artículo. Todos revisaron en forma crítica el artículo y aprobaron la versión final del trabajo.

Fuentes de financiamiento: Instituto Nacional de Salud.

Conflictos de interés: los autores declaran no tener conflictos de interés en la publicación de este artículo.

\section{REFERENCIAS BIBLIOGRÁFICAS}

1. Organización Panamericana de la Salud. Inmunización en las Américas. Resumen 2009. Washington, DC: OPS/ OMS; 2009.

2. Organización Panamericana de la Salud. Plan de acción para la documentación y verificación de la eliminación de sarampión, rubéola y síndrome de rubéola congénita en la Región de las Américas. Washington DC: OPS/OMS; 2009.
3. Dirección General de Epidemiología. Enfermedades inmunoprevenibles. Boletín epidemiológico semanal. 2008;53:965-86.

4. Perú, Ministerio de Salud. Campaña Nacional de Vacunación para la Eliminación de la Rubéola y el Síndrome de Rubéola Congénita (SRC): Informe final 2006. Lima: MINSA; 2006.
5. Perú, Ministerio de Salud. Norma técnica de salud que establece el esquema nacional de vacunación. NTS No 080 - MINSA/DGSP V.02. Lima: MINSA; 2011.

6. Whittembury A, Ticona M, Sanguinetti L, Vargas M, Bolarte J, Arrasco J, et al. Reporte de una intervención frente a un caso importado de sarampión en el Perú, mayo de 2008. Rev peru epidemiol. 2009;13(1):1-9. 
7. Perú, Ministerio de Salud. Plan de la Campaña Nacional de Vacunación contra la Hepatitis B. Lima: MINSA; 2008.

8. Instituto Nacional de Salud. Prevalencia de la hepatitis B y Delta en los pueblos Kandozi y Chapra del Datem del Marañón de los distritos del Morona y Pastaza, provincia Datem del Marañón, Región Loreto, Perú. Lima: INS; 2010.

9. Organización Panamericana de la Salud. Curso de gerencia para el manejo efectivo del Programa Ampliado de Inmunización (PAI). Módulo II: Vacunas del PAI. Washington, DC: OPS/OMS;.2006.

10. Perú, Ministerio de Salud. Coberturas de vacunación por departamento, Perú 2010 [Internet]. Lima: MINSA; 2010 [citado el 12 de julio del 2012]. Disponible en: ftp://ftp. minsa.gob.pe/oei/inmunizaciones/ inmunizaciones_2010

11. Instituto Nacional de Estadística e Informática. Perú: Encuesta Demográfica y de Salud Familiar. Endes continua 2010. Lima: INEI; 2011.

12. World Health Organization. STEPS Sample Size Calculator and Sampling Spreadsheet [Internet]. Geneva: WHO; c2012 [citado el 12 de julio del 2012]. Disponible en: http:// www.who.int/chp/steps/resources/ sampling/en/index.html
13. Villar LM, de Oliveira JC, Cruz HM, Yoshida CF, Lampe E, Lewis-Ximenez LL. Assessment of dried blood spot samples as a simple method for detection of hepatitis B virus markers. J Med Virol. 2011;83(9):1522-9.

14. Mercader S, Featherstone D, Bellini WJ. Comparison of available methods to elute serum from dried blood spot samples for measles serology. J Virol Methods. 2006;137(1):140-9.

15. Parker SP, Cubitt WD. The use of the dried blood spot sample in epidemiological studies. J Clin Pathol. 1999;52(9):633-9.

16. Zhuang H, Coulepis AG, Locarnini SA, Gust ID. Detection of markers of hepatitis B infection in serum dried on to filter-paper: an application to field studies. Bull World Health Organ. 1982;60(5):783-7.

17. Wassilak SG, Bernier RH, Herrmann KL, Orenstein WA, Bart KJ, Amler R. Measles seroconfirmation using dried capillary blood specimens in filter paper. Pediatr Infect Dis. 1984;3(2):117-21.

18. Sander J, Niehaus C. Screening for rubella $\operatorname{IgG}$ and $\operatorname{IgM}$ using an ELISA test applied to dried blood on filter paper. J Pediatr. 1985;106(3):457-61.

19. Riddell MA, Byrnes GB, Leydon JA, Kelly HA. Dried venous blood samples for the detection and quantification of measles $\mathrm{IgG}$ using a commercial enzyme immunoassay. Bull World Health Organ. 2003;81(10):701-7.

20. Samoilovich EO, Svirichevskaia E, Ermolaev MA. [Comparative assessment of determination of measles virus $\operatorname{IgG}$ antibodies in blood serum and dried whole blood]. Vopr Virusol. 2008;53(1):46-8. [Article in Russian].

21. Centers for Disease Control and Prevention (CDC). Global Routine vaccination coverage, 2010. MMWR Morb Mortal Wkly Rep. 2011;60(44):1520-2.

22. Verla-Tebit E, Zhu X, Holsinger E, Mandalakas AM. Predictive value of immunization records and risk factors for immunization failure in internationally adopted children. Arch Pediatr Adolesc Med. 2009;163(5):473-9.

23. Burton A, Monasch R, Lautenbach B, Gacic-Dobo M, Neill M, Karimov R, et al. WHO and UNICEF estimates of national infant immunization coverage: methods and processes. Bull World Health Organ. 2009;87(7):535-41.

24. Cabezas C. Situación y control de la hepatitis B y Delta en el Perú. Acta Med Per. 2008;25(2):96-112.

Correspondencia: Victor Fiestas Solórzano Dirección: Calle Cápac Yupanqui 1400, Lima 11, Perú.

Teléfono: (511) 748-0000 anexo 2143

Correo electrónico: vicfiso@yahoo.es

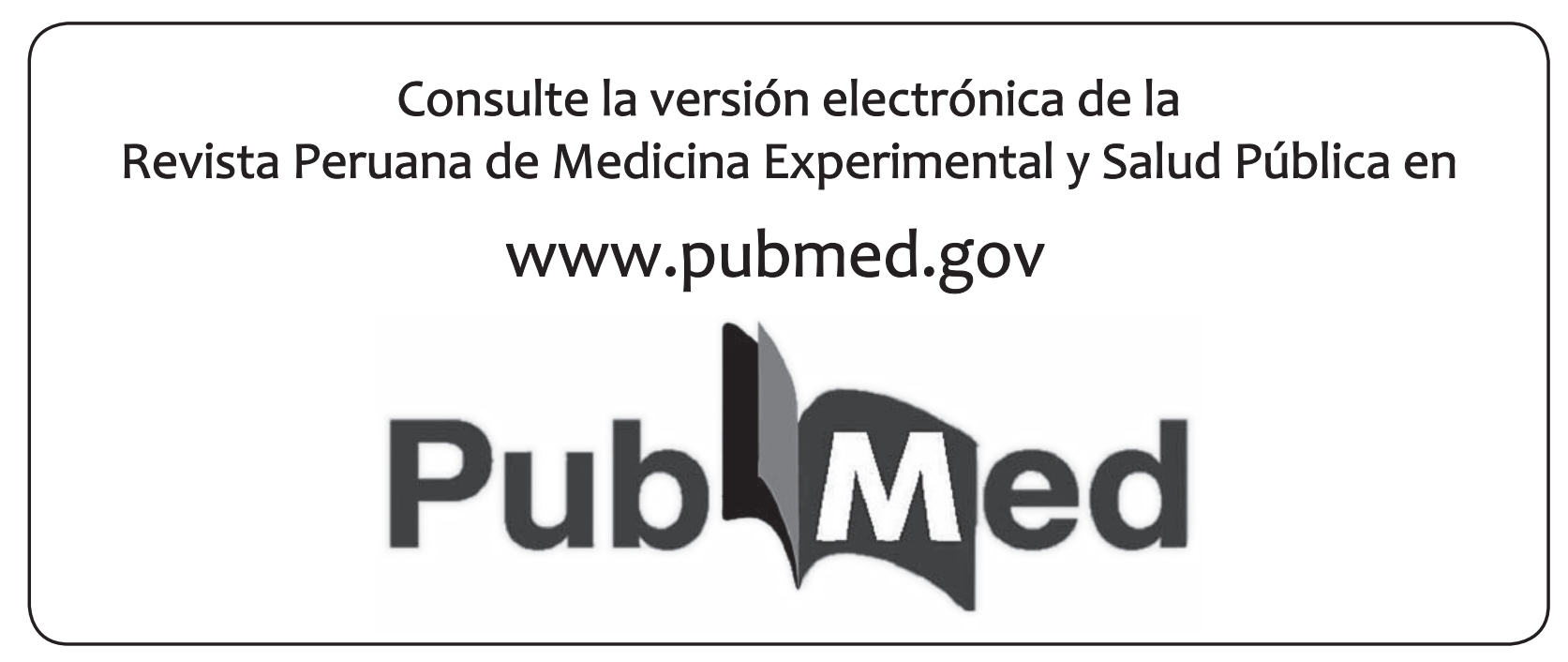

